\title{
The impact of climate change on tourism in Egypt as perceived by both policymakers and tourism managers
}

\author{
I. Shaaban \& Y. Ramzy \\ Hotels and Tourism Department, \\ Arab Academy for Science and Technology and Maritime Transport, \\ Egypt
}

\begin{abstract}
There is evidence indicating that global climate has changed and is anticipated to continue to change over the $21^{\text {st }}$ century and beyond. With its close connections to the environment and climate itself, tourism is considered to be a highly climate sensitive sector similar to agriculture and transportation. The regional manifestations of climate change will be highly relevant for tourism destination and tourist alike, requiring adaptation by all major tourism stakeholders. Tourism can play a significant role in addressing climate change, if the innovation and resources of this vital global economic sector are fully mobilized and oriented toward this goal. This paper examines the views of Egyptian policymakers and tourism managers on potential climate change impacts on Egypt's tourism industry, and their policies and action plans in response to such impacts. The paper concludes with a number of adaptation strategies that Egyptian tourism policymakers and tourism managers could adopt to mitigate the effects of climate change. The importance of this paper lies in understanding and analyzing how climate change impacts Egypt as a destination from perspectives of both policymakers and the industry.
\end{abstract}

Keywords: climate change, environment, tourism, mitigation, strategies, policymakers, tourism managers.

\section{Introduction}

International tourism is the largest and most rapidly expanding economic activity in the world. The global tourism industry is expected to grow significantly in the 
future as personal income, leisure time increase and transportation networks improve (Hamilton et al. [1]). However, tourism is a very sensitive industry that was greatly affected in the past by many challenges such as terrorist attacks, pandemic outbreaks, and natural disasters that took place in some destinations. The new challenge that tourism may be facing nowadays is climate change.

In climate change, the tourism industry is now confronted by a new challenge. Unlike, natural disasters or terrorist attacks, this is not just a short term effect that could be quickly recovered. Rather climate change will permanently alter the attraction of some holiday regions and force them to take steps to adapt in the next few decades. It is evident that there will be regional and seasonal shifts in both national and international tourist flows during the next few decades UNWTO [2]. As a result, there will be winners and losers from climate change. Climate change is unlikely to be a homogeneous force, and its consequences are likely to vary among different locations depending on the magnitude and speed of change, and the characteristics of existing biological and human systems (Wall [3]). In particular, it has been suggested that although most nations may suffer deleterious consequences from climate change, small island states may face the most dire and immediate consequences (Burns [4]). The IPCC [5] also noted that "small island states constitute a very high-risk group of countries as a consequence of their high vulnerability and low adaptive capacity."

\section{Climate change and tourism}

Natural beauty and climate are of universal importance in defining destinations attractiveness (Hu and Ritchie [6]). A good climate is one of the main destination attributes listed in Shoemaker's study [7]. Climatic factors, especially those of reliable summer weather, are the prime motivation for mass leisure travel. Their impact on other forms of leisure travel varies in importance. Travel for business purposes, and to some extent, travel in order to visit friends and relatives, is less affected by climate [2]. Klenosky's study [8] corroborates with this idea as it found that a warm climate is important for those interested in relaxing and having a sun tan.

Nevertheless, climate is one of the main drivers of international tourism, as the majority of tourists seek to relax in the sun or the snow (Aguiló et al. [9]). However, climate did not make it into the seven most important factors from a group of 53 pull factors selected using factor analysis by Yuan and MacDonald [10]. Pike [11] carried out a review of 142 destination image papers, which were published in the period 1973-2000. Only one of these specifically dealt with weather as an important factor of destination choice. This paper was a study by Lohmann and Kaim [12], who noted that there is a lack of empirical evidence on the importance of weather/climate on destination choice decision making. Weather was ranked third after landscape and price, which indicates that although weather is an important factor, destinations are chosen despite of their likely bad weather.

The tourism industry and destinations are clearly sensitive to climate variability and change (Becken and Hay [13], IPCC [14], Gossling and Hall [15], 
Scott [16], and [2]). Climate defines the length and quality of tourism seasons and plays a major role in destination choice and tourist spending. In many destinations tourism is closely linked with the natural environment. Climate affects a wide range of the environmental resources that are critical attractions for tourism, such as snow conditions, wildlife productivity and biodiversity, water levels and quality. Climate also has an important influence on environmental conditions that can deter tourists, including infectious disease, wildfires, insect or water-borne pests (e.g., jellyfish, algae blooms), and extreme events such as tropical cyclones.

There are four broad categories of climate change impacts that will affect tourism destinations, their competitiveness and sustainability.

First, directly through climate variability and changing weather pattern affecting the planning of programs and daily operations, and even health and safety (UNWTO [17]). Indeed, climate is a principal driver of global seasonality in tourism demand, and has an important influence on operating costs, such as heating- cooling, irrigation, food and water supply and insurance cost. Thus, changes in the length and quality of climate dependant tourism seasons could have considerable implications for competitive relationships between destinations and therefore the profitability of tourism enterprises (Amelung et al. [18]).

Second, indirectly by altering the natural environment that represents both a key attraction and basic resources for tourism. A wide range of climate- induced environmental changes will have profound effects on tourism at the destination and regional level. Changes in water availability, biodiversity loss, reduced landscape aesthetic, altered agriculture production, increased natural hazards, coastal erosions and inundation, and damage to infrastructure will all impact tourism to varying degrees.

Impacts of mitigation policies on tourist mobility: National or international mitigation policies - that are policies that seek to reduce GHG emissions - are likely to have an impact on tourist flows. They will lead to an increase in transport costs and may foster environmental attitudes that lead tourists to change their travel patterns (e.g., shift transport mode or destination choices). There has been substantial recent media coverage on this topic, specifically as it relates to air travel. To many in the air industry it has appeared that many politicians and regulators have presumptions in favour of rail over rail transport (Sommerville [19]).

Third, indirect societal change impacts in which climate change is thought to pose a risk to future economic growth and to the political stability of some nations (Barnett [20], Stern [21], and [14]). The Stern Report on the Economics of Climate Change concluded that although a global warming of only 1_C might benefit global GDP, greater climate change would eventually damage economic growth at the global scale, and unmitigated climate change could cause a reduction in consumption per capita of $20 \%$ later in the 21 st century or early (22nd century German Advisory Council on Global Change [22]). The German Advisory Council on Global Change noted that any such reduction of global GDP due to climate change would reduce the discretionary wealth available to 
consumers for tourism and have negative implications for anticipated future growth in tourism; however there has been no in-depth interpretation of the Stern Report for the tourism sector.

Climate change would substantially affect tourism, something that is largely ignored in the literature on climate change impacts e.g. Smith et al. [23], Scott et al. [24], even though tourism is now the largest industry in the world and is still growing quickly. Tourism has a strong impact on the environment [15], and a substantial impact on climate.

The tourism sector represents the primary user of air transport. Concomitantly, air transport is the primary contributor to GHG emissions in the tourism sector. Air transport is estimated as contributing about $40 \%$ of carbon dioxide emissions from the tourism sector. In fact, aircraft engines produce emissions that are similar to other emissions resulting from fossil fuel combustion but which are unusual in that a significant proportion is emitted at altitude, giving rise to important environmental concerns regarding their global impact (UNWTO [26]).

Moreover, all demand and supply facets of tourism are regarded as being affected by global climate change. Within the tourism generating regions climate changes affects the tourism decision making process in a number of different ways. Climate change can directly impact tourist behavior because of changed perceptions not only of the climate appeal and image of certain destination, but also the activities that can be engaged in Hall and Higham [26]. Hamilton et al. [1] found that locations that are cool at present would attract more tourists under global warming and that currently warm places would attract fewer tourists. There are changes in the strengths of the pull effect of international destinations; however are tempered by changes in the strengths of the push effect of the home country. At a broad scale of analysis climate change will likely mean not that people will stop travelling but they will change their travel preferences in both space and time [27].

Although research into the impacts of climate change for tourism at a primitive stage, it is generally acknowledged that there would be major consequences for the tourist industry [19]. However, Hamilton et al. [27] concluded that climate change may well affect the patterns of tourism rather than the number of tourists. Hence, climate change which would lead to a gradual shift of tourist destinations; or the possibility of substitution between destinations.

Therefore, the current research focuses on exploring the impacts of climate change on Egypt as a tourist destination, through investigating views of policy makers and tourism managers in Egypt on potential climate change consequences on the tourism industry in Egypt, and the policies they prefer to use in order to adapt to the climate changes that Egypt is expecting to face.

\section{Climate change in Egypt}

Egypt occupies the northeastern corner of Africa. It is bounded in the east by the Red Sea, in the west by Libya, in the north by the Mediterranean Sea and in the 
south by Sudan. The total land area is 997,688 square kilometers that comprise five major geographical regions: the Nile Valley, the Nile Delta, the Eastern Desert, Sinai and the Western Desert (Strzepek et al. [28]). The coastline extends for more than 3500 kilometers along the Mediterranean Sea and the Red Sea coasts. The Nile Delta coast which constitute about 300 kilometers, hosts a number of highly populated cities such as Alexandria, Portsaid, Rosetta and Damietta.

Egypt's climate is semi-desert, characterized by hot dry summer, moderate winter and little rainfall. The country has areas with strong wind, especially along the Mediterranean and Red Sea coasts. Sites with an annual average wind speed of 8.0-10.0 meter/ second have been identified along the Red Sea coast and about 6.0-6.5 meter/ second along the Mediterranean coast (Agrawala et al. [29]). In fact, there is evidence that there is steady increase in temperature in Egypt. More warming is estimated for summer than for winter, and annual precipitation is estimated to fall. Scientific evidence and climate records have sharpened the focus on the relationship between the concentrations of GHG in the atmosphere and the rise in temperature. Therefore, this will cause sea level to rise and decrease the amount and the amount and pattern of precipitation.

Egypt recognizes its own vulnerability to climate change in vital areas threatening the sustainability of its natural and socioeconomic systems. Egypt is among the first Arab countries to join the cooperative global efforts to confront climate change threats. Although GHG in Egypt do not exceed $0.6 \%$ of world total emissions, it will be highly affected by potential climate changes. Indeed, since the Rio de Janeiro Earth Summit in 1992, Egypt ratified the United Nations Framework Convention on Climate Change (UNFCC) in 1994 and accordingly Egypt has prepared a National Action Plan on Climate Change to coordinate its efforts to face this serious and important challenge. Moreover, in 1999 Egypt signed the Kyoto Protocol (which aim to help member parties to reduce their emissions) [30].

In spite of the fact that Egypt is highly affected by climate change, there are no accurate studies on the negative impacts that could occur in Egypt due to climate change. However, the sea level rise threatens Egypt's long coastal stretch on the Mediterranean and the Red sea with potential damages to the ecosystem in general and the tourism industry in particular. Moreover, there are predicted socioeconomic implications due to human migration, land loss and soil salinity. Additionally, the rise in temperature of sea water causes damage of marine life and coral reef bleaching.

Egypt as a tourist destination is characterized by its mild temperature in winter, thus the effects of climate change in Egypt will mainly be in the summer months, as they are faced with loss of comfort resulting from rising temperatures and with water shortages. However, the country is well known for high temperatures in the summer months, so that holiday makers have higher tolerance. In fact, Egypt benefits from a very balanced pattern of tourist arrival all over the year (International Western tourists in winter and Arab tourists in summer). 
However, several types of tourism are dominating the international tourism market in Egypt and will be affected by the climate change. These changes could be as follows:

First, recreational or beach tourism is a dominating market segment especially in Sinai Peninsula and the Red Sea. This coastal zone of Egypt is most vulnerable to the sea level rise due to its relatively low elevation. It is also affected by salt water intrusion and extreme dust storms. This will pose threats on the existing tourism investment.

Second, diving tourism depends mainly on the coral reefs in the Red Sea. The high temperature of sea water leads to the bleaching of coral reefs, which is considered a natural wealth attracting tourists [30].

On the other hand, there are other types of tourism in Egypt, which are less susceptible to climate change (DB Research [30]) such as; the Cairo area, with the pyramids of Giza and tours on the Nile and to the Pharaohs tombs in the Valley of Kings.

\section{Methodology}

This study focuses on the impacts of climate change on tourism in Egypt. It uses a detailed assessment of the views of selected actors of specific connections among climate change, tourism, and tourism related policies. First, it examines the potential impacts of climate change for tourism in Egypt. It is considered a useful case study because, there is little published research on the potential repercussions of climate change on tourism and nearly nothing deals with tourism in Egypt. Second, the study considers views on this topic for two groups of actors: actors who might be involved in developing public policies related to tourism and climate change, and diverse managers working in the tourism industry, largely in the private sector such as tour operators and hotel managers. This involved the use of semi structured interviews and also "official" policy statements and advice. The third objective is to assess the opinions of these two groups of actors on the likelihood (or possible risks) of different types of climate change impacts relevant to tourism.

Semi-structured interviews were used to examine views on the likely impacts of climate change on the tourism industry in Egypt and on the preferred policies in response to climate change issues. The interviews were administered in November and December 2009 to two groups of actors on the country: policy makers and tourism industry managers, the latter largely being in the private sector.

Five policy makers in government and ten key private sector industry associations and businesses, were interviewed. They were selected to include organizations with strategic influence on policy making that directly or indirectly affect the tourism sector. They were actors who might be involved in developing future public policies related to tourism and climate change. Included from the government were policy makers from the Ministry of Tourism, Ministry of State for Environmental Affairs, and from the private sector there were tour operators, and hotel and resort managers. 
These policy makers were interviewed using a semi-structured approach, with the interviews being tape recorded. The research uses Qualitative content analysis in analysing the data drawn out from the interviews. Qualitative content analysis is probably the most prevalent approach to the qualitative analysis of documents or interview transcripts. It comprises a searching out of underlying themes in responses being analysed. In addition, reports and studies by the Egyptian government were examined for "official" explanations of potential global warming impacts and policy options. These include documents on climate change produced by the Egyptian Environmental Affairs Agency (EEAA), which is responsible for preparing the necessary plans for Environmental protection and Environmental development projects.

\section{Discussion}

\subsection{The impacts of climate change on tourism industry in Egypt as perceived by the industry}

Respondents were asked about their opinions about global climate change. Eight of ten agreed that global climate change is a reality, two being uncertain about its consequences and the time upon which such impacts would take place.

They were also asked about the impacts they considered climate change might have on tourism in Egypt. The replies represent perceived risks relevant to the industry. Most replies focused on the impacts on the marine environment. On the other hand, nearly all respondents agreed that the impacts of climate change would not have severe effects on tourism in Egypt. Some respondents asserted that rising temperatures could increase seasonal differences: as a result, seaside tourists would increasingly avoid the summer months, while the tourist high season in Egypt is winter, benefiting from of the seaside resorts on the red sea, which are considered winter resorts, due to the climate convenience during the winter season.

Other respondents agreed that the proximity of Egypt from the Western European countries is considered a benefit especially for winter travelers and its proximity from the Arab countries for those travelers trying to get away from the summer heat at home to a destination with lesser temperature. Respondents were asked about their views on the effect of climate change on tourists' flows to Egypt. Nine respondents agreed that climate change would not have a severe effect on the number of tourists, but it may change the patterns of tourism itself in terms of seasonality and the types of tourists. On the other hand, one respondent asserted that there would not be any impact on tourists' flows.

Respondents were finally asked about their views of the actions that should be taken in order to counteract the negative impacts of climate change. Their responses emphasized the importance of adopting "Green" practices in operation. They also highlighted the importance of environmental communication among various stakeholders. 


\subsection{Climate change and tourism industry in Egypt as perceived by policy makers}

Policy makers were asked about their views of the most likely impacts that would affect tourist destinations in Egypt. They asserted that there are several challenges facing the environmental action in Egypt, and particularly some affecting the tourism activity such as the rise of sea level and the damage that may affect coastal tourism facilities.

They were also asked about actions necessary to respond to climate change impacts on tourism industry in Egypt. All respondents agreed on emphasizing that the climate change problem is taken seriously by the Egyptian authorities. For example, authorities are spending US \$300 million to construct concrete sea walls to protect beaches from rising seas in the city of Alexandria.

The Egyptian Environmental Affairs Agency (EEAA) reported that Egypt's Ministry of state for Environmental affairs is preparing a "National Strategy Study" on adaptation including a vulnerability index to pinpoint the most endangered regions.

The EEAA also mentioned that several measures could be utilized to deal with the impact on the coastal zone corridor, including beach nourishment (disposition of sand onto the beach), construction of breakwaters, setting regulations to restrict development in vulnerable areas, changes in land use and integrated coastal zone management (ICZM), which embraces the general principles of environmental management adopted by the UN conference on Environment and Development.

Moreover, policy makers affirmed that the Action Plan for Climate Change that the Egyptian government is adopting includes national goals about the necessity of exchanging information to reach to the core of climate change phenomenon and its environmental impacts. One of its main axes is cooperation with International Community to maintain environmental quality and reduce climate change causes. The plan includes various fields; raising public awareness about it, its economic dimensions and how to deal with it, capacity building, international financial and technical aid, and technology transfer. Moreover, policy-making and needed programs for adaptation with its impacts in all sectors, and the participation of Non-Governmental Organizations (NGOs).

In addition, they mentioned governmental strategies for raising public awareness and setting a policy for environmental communication among the various sectors in the country.

They finally, concluded that the Egyptian government is taking several actions in cooperation with global communities to protect the risked areas and to decrease the effects of the climate change by serious research work and setting new environmental regulations.

\section{Conclusion}

The potential impacts of climate change, such as sea level rise, have given rise to considerable concern. Many respondents felt that damage to coastal tourism 
facilities was very likely, with notable proportions also considering it very likely that there will be beach changes, sea level rise, and damage to marine ecosystems. The tourism industry managers and policy makers shared many similar views on these impacts. More of the managers in the industry, however, considered it likely that there would not be impacts on the volume of tourists but rather on the patterns of tourism itself. Both the policy makers and tourism industry managers identified increasing public awareness as the most appropriate policy response to the impacts of climate change on tourism in Egypt.

There is a great emphasis on the serious actions that Egypt is taking to protect its future generations from major threats. Egypt has prepared a national action plan on climate change to coordinate its efforts to face this serious and important challenge, to maintain its sustainable economic development and to provide a safe environment for its future generations.

\section{References}

[1] Hamilton, J. M., Maddison, D. \& Tol, R. Climate Change and International Tourism: A stimulation study, Global Environmental Change, 15, pp. 253266,2005

[2] UNWTO, Climate Change and Tourism: Proceeding of the First International Conference on Climate Change and Tourism, Djerba, Tunisia, World Tourism Organization, Madrid, Spain, 2003

[3] Wall, G., Implications of Global Climate Change for Tourism and Recreation in Wetland Areas, Climate Change, 40, pp. 371-389, 1998

[4] Burns, W., The impact of Climate Change on Pacific Island Developing Countries in the $21^{\text {st }}$ Century. In Gillespie, A. \& Burns, W. (eds.) Climate Change in the South Pacific: Impacts and Responses in Australia, New Zealand and Small State Island, pp. 233-250, Kluwer, Netherlands, 2000

[5] IPCC, Climate Change 2001: The Scientific Basis. Contribution of Working Group 1 to the Third Assessment Report of the IPCC, Cambridge University Press, Cambridge, UK, 2001

[6] Hu, Y. \& Ritchie, J.R.B., Measuring Destination Attractiveness: A Contextual Approach, Journal of Travel Research, 23(2), pp. 25-34, 1993

[7] Shoemaker, S., Segmenting the US Travel Market according to benefits realized, Journal of Travel Research, 32(3), pp. 8-21, 1993

[8] Klenosky, D.B., The "Pull" of Tourism destinations: A Means-end Investigation, Journal of Travel Research, 40(4), pp. 385-395, 2002

[9] Aguilo, E., Alegre, J. \& Sard, M. The Persistence of the Sun and Sand Tourism Model, Tourism Manage, 26, pp. 219-231, 2005

[10] Yuan, S. \& MacDonald, C., Motivational Determinants of International Pleasure Time, Journal of Travel Research, 29(1), pp. 42-44, 1990

[11] Pike, S., Destination Image Analysis-A review of 142 papers from 1973 to 2000. Tourism Management, 23, pp. 541-549, 2002

[12] Lohmann, M. \& Kaim, E. Weather and Holiday Destination Preferences, Image Attitude and Experience, The Tourist Review, 2, pp. 54-64, 1999 
[13] Becken, S. \& Hay, J., Tourism and Climate Change- Risks and Opportunities, Channel View Publications, Cleveland, 2007

[14] IPCC, Climate Change 2007: Mitigation of Climate Change, Contribution of Working Group III to the Fourth Assessment Report of the Intergovernmental Panel on Climate Change, Cambridge University Press, Cambridge, UK, 2007

[15] Gossling, S. \& Hall, C. M. An Introduction to Tourism and Global Environmental Change. In Gossling, S., Hall, C. M. (eds.) Tourism and Global Environmental Change, pp. 1- 34, Routledge, London, 2006

[16] Scott, D., Climate Change and Sustainable Tourism in the $21^{\text {st }}$ Century. In Cukiar, J. (eds.) Tourism Research: Policy, Planning and Prospects, pp. 174-248, University of Waterloo, Waterloo, 2006

[17] UNWTO, Climate Change and tourism: Responding to Global Challenges, Advanced Summary, World Tourism Organization, Madrid, Spain, 2007

[18] Amelung, B., Nicholls, S., \& Viner, D. Implications of Global Climate Change for Tourism Flows and Seasonality, Journal of Travel Research, 45, pp. 285-296, 2007

[19] Sommerville, H., Travel, Tourism and the Environmental Changes, Tourism and Hospitality Research, 5 (1), pp. 65-71, 2003

[20] Barnett, J., Security and Climate Change, Tyndell Center Working Paper, Number Seven, 2001

[21] Stern, N., The Economics of Climate Change: The Stern Review, Cambridge University Press, Cambridge, United Kingdom, 2006

[22] German Advisory Council on Global Change, World in Transition: Climate Change as a Security Risk, Berlin, Germany , 2007

[23] Smith, J. B., Schelunhuber H. J., Mirza, M.M. \& Fankhauser S., Vulnerability to Climate Change and Reasons for Concern: A Synthesis. In McCarthy, J. J., Canzian O. F., Leary, N. A. (eds.) Climate Change 2001: Impacts, Adaptation and Vulnerability, pp. 913-967, Cambridge University Press, Cambridge, 2001

[24] Scott, D., McBoyle, G.\& Schwartzentruber, M., Climate Change and the Distribution of Climatic Resources for Tourism in North America, Climate Research, 27(2), pp. 105- 117, 2004

[25] UNWTO, Tourism, Air Transport and Climate Change, A World Tourism Organization Discussion Paper, Madrid, Spain, 2007

[26] Hall, C. M., Higham, J. E., Introduction: Tourism, Recreation and Climate Change. In Hall, C. M., Higham, J. E. (eds.) Tourism, Recreation and Climate Change, pp. 3-28, Channel View Publications, United Kingdom, 2005

[27] Hamilton, J. M., Maddison, D. \& Tol, R., Effects of Climate Change on International Tourism, Climate Research, 29, pp. 245-254, 2005

[28] Strzepek, K. N., Onyeji, S., Saleh, M. \& Yates, D., an Assessment of Integrated Climate Change impacts on Egypt. In Strzepek, K. N. \& Smith, J., As Climate Change: International Impacts and Implications, Cambridge University Press, USA. 
[29] Agrawala, S., Moehner, A., ElRaey, M., Conway, D., Aalst, M., Hagenstad, M. \& Smith, J., Development and Climate Change in Egypt" Focus on Coastal Resources and the Nile, Environment Directorate Environment Policy Committee, OECD, 2004.

[30] DB, Climate Change and Tourism: Where will the journey lead?, Current Issues, Deutsch Bank Research, 2008. 